\title{
Corticotropin-releasing Factor
}

\section{Mechanisms to Inhibit Gastric Acid Secretion in Conscious Dogs}

\author{
H. Jurgen Lenz \\ Division of Gastroenterology, Department of Medicine, University of California, \\ San Diego Medical Center, San Diego, California 92103
}

Stephen E. Hester and Marvin R. Brown

Clayton Foundation Laboratories for Peptide Biology, The Salk Institute, La Jolla, California 92037

\begin{abstract}
Immunoreactivity similar to that of corticotropin-releasing factor (CRF) is found in regions of the central nervous system that modulate autonomic responses, including gastrointestinal functions. We examined the central nervous system effects of ovine CRF on gastric acid secretion in conscious dogs. Male beagle dogs (11-13 kg) were fitted with chronic intracerebroventricular cannulae and gastric fistulae. Gastric acid secretion in response to intravenously administered gastric secretory stimuli was measured by in vitro titration of gastric juice to pH 7.0 and in response to an intragastric meal by in vivo intragastric titration at pH 5.0. Plasma gastrin was determined by radioimmunoassay. CRF microinjected into the third cerebral ventricle decreased pentagastrin-stimulated gastric acid secretion for 3 h $(P<0.01)$ dose-dependently $\left(0.2-6.0 \mathrm{nmol} \cdot \mathrm{kg}^{-1}\right)$. CRF did not inhibit histamine-stimulated gastric secretion but significantly $(P<0.01)$ decreased the secretory response after 2-deoxy-D-glucose for $3 \mathrm{~h}$. The gastric inhibitory action of intracerebroventricularly administered CRF on pentagastrinstimulated gastric acid secretion was completely abolished by ganglionic blockade with chlorisondamine. The opioid antagonist, naloxone, and the vasopressin antagonist, [1-deaminopenicillamine,2-( $\boldsymbol{O}$-methyl)tyrosine,8-arginine]-vasopressin, significantly suppressed the inhibitory effect of CRF on gastric acid secretion stimulated by pentagastrin. In contrast, truncal vagotomy did not prevent the inhibition of gastric acid secretion induced by CRF. CRF (0.2-2.0 $\left.\mathrm{nmol} \cdot \mathrm{kg}^{-1}\right)$ administered intracerebroventricularly decreased gastric acid secretion stimulated by $200-\mathrm{ml}$ liquid meals containing $8 \%$ peptone. CRF did not affect plasma gastrin concentrations. These results indicate that CRF microinjected into the third cerebral ventricle inhibits gastric acid secretion in conscious dogs. CRF-induced inhibition of gastric acid secretion appears to be mediated by the sympathetic nervous system and, in part, by opiate and vasopressindependent mechanisms.
\end{abstract}

A portion of this report was presented at the 85th Annual Meeting of the American Gastroenterological Association, 19-25 May 1984, New Orleans, LA, and has appeared in abstract form (1984. Gastroenterology. 86:1158).

Address correspondence to Dr. Brown.

Received for publication 11 June 1984 and in revised form 13 November 1984

J. Clin. Invest.

(c) The American Society for Clinical Investigation, Inc.

0021-9738/85/03/889/07 \$1.00

Volume 75, March 1985, 889-895

\section{Introduction}

Corticotropin-releasing factor (CRF) ${ }^{1}$ is a 41 -residue peptide isolated from ovine (1) and rat hypothalami (2). The primary structure of human CRF that is identical to the amino acid sequence of rat $\mathrm{CRF}$ was derived from the nucleotide sequence of the cloned DNA (3).

CRF stimulates the release of ACTH and $\beta$-endorphin in vivo and in vitro (1). Furthermore, the distribution of CRFlike immunoreactivity within the central nervous system suggests that CRF-containing pathways in the brain are involved in the mediation of autonomic responses (4). CRF administered intracerebroventricularly (i.c.v.) to rats results in activation of the sympathetic nervous system resulting in elevated plasma catecholamine and glucose concentrations (5) as well as in increased mean arterial pressure and heart rate (6). CRF also increases oxygen consumption (7) and motor activity in the rat (8) but decreases sexual behavior (9), food intake (10), and gastric acid secretion (11). In the dog, CRF administered i.c.v. activates the sympathetic nervous system and increases plasma vasopressin concentrations (12).

The aforementioned central nervous system actions of $\mathrm{CRF}$ and the recent demonstration that a CRF antagonist diminished the ACTH release normally observed after either stress (13) imply that CRF may be involved in generating integrated endocrine and autonomic responses to stress (14).

The purpose of this study was to examine the central nervous system effects of CRF on gastric acid secretion and to study the mechanism(s) of its action in conscious dogs. In particular, we attempted to assess the role of the autonomic nervous system in mediating the biologic actions of CRF on gastric acid secretion.

\section{Methods}

Animal preparation. Male beagle dogs weighing 11-13 kg were obtained from Marshall Laboratories, North Rose, NY. The animals were housed in temperature-, humidity-, and illumination- (from 7:00 a.m. to 7:00 p.m.) controlled quarters and fed Science Diet (Hills' Pet Products, Inc., Topeka, KS).

Surgery was performed under general anesthesia that used nitrous oxide $(30 \%)$ and halothane $(1.2 \%)$ initially, and then halothane $(1.2 \%)$ alone. Stainless steel guide cannulae (22-guage; Plastic Products Co., Roanoke, VA) were implanted using a stereotaxic instrument (David

1. Abbreviations used in this paper: AVP, arginine vasopressin; CRF, corticotropin-releasing factor; i.c.v., intracerebroventricular(ly) 
Kopf Instruments, Tujunga, CA). The i.c.v. guide cannulae were placed so that their tips were inside the third cerebral ventricle. In each dog, cerebrospinal fluid was aspirated, indicating correct i.c.v. placements of the cannulae. The coordinates for the position of the tip of the guide cannula were selected from a stereotaxic atlas (15) and modified: lateral, $0 \mathrm{~mm}$; anterior, $22 \mathrm{~mm}$; superior, $18 \mathrm{~mm}$ as measured from the interaural line. The guide cannula was secured to the skull and four screws were drilled into the parietal bones using dental cement. A dummy cannula was left in place until the time of each experiment.

After a midline abdominal incision, a modified plastic Thomas cannula (16) with an internal diameter of $1 \mathrm{~cm}$ (Research Instruments and Manufacturing, San Diego, CA) was implanted into the most dependent part of the stomach and secured to the gastric wall by a purse string suture. The cannula was exteriorized through a left paramidline abdominal incision and closed with a plastic plug. The abdominal wall was closed in layers, and animals were allowed to recover for $4 \mathrm{wk}$ before the first experiment.

After the initial studies were completed, bilateral, subdiaphragmatic truncal vagotomy, and a Heineke-Mikulicz pyloroplasty (17) were performed in the same four dogs that were used in the prior experiments (kindly performed by Dr. Richard P. Saik, Department of Surgery, Veterans' Administration Medical Center, San Diego, CA). 2-3 cm of each vagal trunk and all visible ramifications were resected. The animals recovered for $4 \mathrm{wk}$ before the next study was performed.

I.c.v. injection. Synthetic ovine CRF was obtained from Dr. Jean E. Rivier (The Salk Institute, La Jolla, CA). The peptide was dissolved in deionized water, aliquoted (3-90 nmol per coned plastic tube), lyophilized (Speed Vac Concentrator, model SVG 100, Savant Instruments, Inc., Hicksville, NY), and stored frozen at $-20^{\circ} \mathrm{C}$. At the day of the experiment, the peptide was dissolved in sterile water so that each dose was administered in a final volume of $10 \mu \mathrm{l}$. Using a 50- $\mu \mathrm{l}$ syringe (Hamilton Co., Reno, NV) connected to the injection cannula with polyethylene tubing (PE-50), $13 \mu \mathrm{l}$ of the dissolved peptide was aspirated. The dummy cannula was removed from the third ventricle guide cannula and replaced by the injection cannula. By employing a syringe pump (model 341; Sage Instruments, Inc., White Plains, NY), $10 \mu \mathrm{l}$ of the aspirate was injected for a 1-min period while the additional $3 \mu \mathrm{l}$ remained inside the PE tubing and the top of the injection cannula was closed with the cut end of a pipette tip. $15 \mathrm{~min}$ later, the injection cannula was removed and the dummy cannula was screwed onto the guide cannula. In control experiments, $10 \mu \mathrm{l}$ of the vehicle, sterile water, was injected. CRF or control was injected either at the -15 -min or at the 60 -min time point as indicated in the figures. To assure that sterile water injected i.c.v. did not have any inherent effects on gastric acid secretion, a series of control experiments were performed injecting $10 \mu \mathrm{l}$ of sterile water, $\mathrm{NaCl} 0.15 \mathrm{M}$, or canine cerebrospinal fluid into the third cerebral ventricle. Gastric acid secretion stimulated by pentagastrin $\left(4 \mu \mathrm{l} \cdot \mathrm{kg}^{-1} \cdot \mathrm{h}^{-1}\right)$ was similar after injection of each of the three control solutions, indicating that sterile water used as control did not affect the gastric secretory responses.

Measurement of acid secretion in response to intravenous stimuli. The animals were fasted overnight for $18 \mathrm{~h}$ but had free access to water until the beginning of the experiment. During the tests, the animals were placed in nylon harnesses (Alice King Chatham Medical Arts, Los Angeles, CA). The plug of the gastric fistula was removed and a plastic vial $\left(50 \mathrm{~cm}^{3}\right)$ for collection of gastric juice was attached by an adapter to the gastric fistula. The animals were not studied when food particles were found upon opening of the gastric fistula. An indwelling intravenous plastic catheter (Abbocath-T 20-gauge; Abbott Hospitals, Inc., North Chicago, IL) was inserted into the vein of a front leg. After a 60-min equilibration period, gastric secretagogues, dissolved in $0.15 \mathrm{M} \mathrm{NaCl}$, were infused intravenously at a constant rate $\left(3 \mathrm{ml} \cdot \mathrm{h}^{-1}\right)$ using an infusion pump (model 352; Sage Instruments, Inc., White Plains, NY): pentagastrin, $4 \mu \mathrm{g} \cdot \mathrm{kg}^{-1} \cdot \mathrm{h}^{-1}$ (Peptavlon; Ayerst Laboratories, Inc., New York); histamine phosphate, 80 $\mu \mathrm{g} \cdot \mathrm{kg}^{-1} \cdot \mathrm{h}^{-1}$ (Eli Lilly \& Co., Indianapolis; IN); and 2-deoxy-Dglucose, $100 \mathrm{mg} \cdot \mathrm{kg}^{-1} \cdot 3 \mathrm{~min}^{-1}$ (Calbiochem-Behring Corp., La Jolla,
CA). Gastric juice was collected by gravity drainage in 15 -min periods, and the volume was measured to the nearest milliliter. A 1-ml aliquot was titrated in vitro with $0.1 \mathrm{~N} \mathrm{NaOH}$ to $\mathrm{pH} 7.0$ on an automatic titrator (Radiometer, Copenhagen, Denmark) and the gastric acid output calculated (18).

In some experiments, the effects of ganglionic blockade, a vasopressin, and an opioid receptor antagonist on pentagastrin-stimulated gastric acid secretion were examined. The following substances were injected intravenously as a bolus at the zero time point: Chlorisondamine, a ganglionic blocking agent, $0.5 \mathrm{mg} \cdot \mathrm{kg}^{-1}$ (Ciba Pharmaceutical Co., Summit, NJ); [1-deaminopenicillamine,2-( $O$-methyl)tyrosine,8arginine]-vasopressin, a vasopressin antagonist, $200 \mathrm{nmol} \cdot \mathrm{kg}^{-1}$ (obtained from Dr. Jean E. Rivier, The Salk Institute); naloxone, an opioid antagonist, $1 \mathrm{mg} \cdot \mathrm{kg}^{-1}$ (Endo Laboratories, Wilmington, DE). Saline, $0.15 \mathrm{M} \mathrm{NaCl}$, given intravenously served as control.

Measurement of acid secretion and plasma gastrin in response to intragastric meals. After an ovefnight fast, the animals were allowed to equilibrate in the harness for at least $0.5 \mathrm{~h}$. An indwelling intravenous plastic catheter was inserted into the vein of a front leg to facilitate blood draws. $15 \mathrm{~min}$ after i.c.v. administration of CRF, a liquid test meal, $200 \mathrm{ml}$, containing $16 \mathrm{~g}$ of peptone (Bacto-Peptone; Difco Laboratories, Detroit, MI) was instilled by gravity through an 18French double lumen tube (Salem sump tube; Argyle, St. Louis, MO) into the stomach. The osmolality of the peptone meal was 310 mosmol $\cdot \mathrm{kg}^{-1}$, and the $\mathrm{pH}$ was adjusted with $1 \mathrm{~N} \mathrm{HCl}$ to 5.0 . Gastric acid secretion was measured for $2 \mathrm{~h}$ by in vivo automatic intragastric titration at $\mathrm{pH} 5.0$ by the addition of $0.1 \mathrm{~N} \mathrm{NaOH}(19)$.

$1 \mathrm{ml}$ of venous blood was obtained at the intervals indicated in Fig. 9, collected in chilled tubes containing $50 \mu \mathrm{l}$ of $0.5 \mathrm{M}$ EDTA, centrifuged at $4^{\circ} \mathrm{C}$ for $10 \mathrm{~min}$, and plasma was stored at $-20^{\circ} \mathrm{C}$. Plasma gastrin concentrations were determined by radioimmunoassay using an antibody, 1611, that measured both gastrin 17 and gastrin 34 and had $<3 \%$ cross-reactivity with cholecystokinin (20). Measurements were kindly performed by Dr. F. J. Ho and Mr. P. Chew in the laboratory of Dr. John $\mathrm{H}$. Walsh, University of California at Los Angeles, CA.

Validation and reproducibility studies. Validation and reproducibility studies were performed in four fasted dogs. To determine if CRF injected i.c.v. appears in the peripheral circulation, $2 \mathrm{ml}$ of venous blood was obtained before and 10, 20, 40, 60, and $90 \mathrm{~min}$ after i.c.v. administration of CRF $\left(2 \mathrm{nmol} \cdot \mathrm{kg}^{-1}\right)$. CRF-like immunoreactivity was determined in plasma in the laboratory of Dr. Wylie W. Vale (The Salk Institute) as previously described (21). The detection limit of the assay was $1 \mathrm{fmol} /$ tube or $3 \mathrm{fmol} / \mathrm{ml}$ of plasma if $1 \mathrm{ml}$ of dog plasma was extracted (21). No CRF-like immunoreactivity was measured either before or after the injection of CRF, indicating that CRF did not leak out of the cerebroventricular system into the peripheral circulation under the conditions of this study.

To assure completeness of vagotomy, 2-deoxy-D-glucose (100 $\mathrm{mg} \cdot \mathrm{kg}^{-1} \cdot 3 \mathrm{~min}^{-1}$ ) was given intravenously. No gastric secretory responses were observed in these experiments, indicating that vagotomy was complete (22)

To test the effectiveness of ganglionic blockade by chlorisondamine, 2-deoxy-D-glucose $\left(100 \mathrm{mg} \cdot \mathrm{kg}^{-1}\right)$ was infused intravenously during a 3-min period in four animals 0.5 and $3 \mathrm{~h}$ after intravenous administration of chlorisondamine $\left(0.5 \mathrm{mg} \cdot \mathrm{kg}^{-1}\right)$. No gastric secretory responses were observed after 2-deoxy-D-glucose infusion, indicating complete ganglionic blockade of the autonomic nervous system. CRF administered i.c.v. activates the sympathetic nervous system increasing plasma catecholamines and mean arterial pressure $(5,6,12)$. Chlorisondamine injected intravenously completely abolished the rise in plasma catecholamine concentrations and mean arterial pressure $(5,6,12)$ induced by CRF given i.c.v. These findings also indicated that ganglionic blockade with chlorisondamine blocked sympathetic outflow from the central nervous system.

CRF injected i.c.v. increased serum vasopressin in the dog (12). We reported earlier (12) that $150 \mathrm{nmol} \cdot \mathrm{kg}^{-1}$ of the vasopressin 
antagonist, [1-deaminopenicillamine,2-( $O$-methyl)tyrosine,8-arginine]vasopressin, completely abolished the increase in mean arterial pressure induced by intravenous administration of [8-arginine]-vasopressin (AVP $\left.400 \mathrm{pmol} \cdot \mathrm{kg}^{-1}\right)$ in the dog. AVP $\left(1 \mathrm{nmol} \cdot \mathrm{kg}^{-1}\right)$ administered intravenously significantly $(P<0.01)$ decreased the mean $( \pm \mathrm{SE})$ pentagastrinstimulated (4 $\mu \mathrm{g} \cdot \mathrm{kg}^{-1} \cdot \mathrm{h}^{-1}$, intravenously) acid output from $6.6 \pm 0.7$ to $0.3 \pm 0.1 \mathrm{mmol} \cdot 30 \mathrm{~min}^{-1}$. Injection intravenously of the AVP antagonist $\left(220 \mathrm{nmol} \cdot \mathrm{kg}^{-1}\right) 60 \mathrm{~min}$ before intravenous administration of AVP $\left(1 \mathrm{nmol} \cdot \mathrm{kg}^{-1}\right)$ completely abolished the gastric intibitory effect of AVP, indicating that the AVP antagonist did completely block the biological effect of a high dose $\left(1 \mathrm{nmol} \cdot \mathrm{kg}^{-1}\right)$ of vasopressin. AVP $\left(2 \mathrm{nmol} \cdot \mathrm{kg}^{-1}\right)$ administered i.c.v. did not significantly inhibit mean $\left( \pm\right.$ SE) gastric acid secretion stimulated by pentagastrin $\left(8 \mu \mathrm{g} \cdot \mathrm{kg}^{-1} \mathrm{s.c}.\right)$ : 16.4 \pm 1.7 in AVP-treated vs. $19.3 \pm 2.1 \mathrm{mmol} \cdot 2 \mathrm{~h}^{-1}$ in control-treated animals.

CRF released $\beta$-endorphin in vivo (1). $\beta$-Endorphin $\left(1 \mathrm{nmol} \cdot \mathrm{kg}^{-1}\right)$ administered i.c.v. significantly $(P<0.05)$ decreased the mean $( \pm \mathrm{SE})$ pentagastrin-stimulated $\left(4 \mu \mathrm{g} \cdot \mathrm{kg}^{-1} \cdot \mathrm{h}^{-1}\right.$, i.v. $)$ gastric acid output from $8.7 \pm 0.6$ to $4.3 \pm 0.5 \mathrm{mmol} \cdot 30 \mathrm{~min}^{-1}$. Naloxone $\left(1 \mathrm{mg} \cdot \mathrm{kg}^{-1}\right.$, i.v. $)$ injected $60 \mathrm{~min}$ before $\beta$-endorphin administration completely abolished the gastric inhibitory effect of $\beta$-endorphin $\left(1 \mathrm{nmol} \cdot \mathrm{kg}^{-1}\right)$. These results suggest that $\beta$-endorphin inhibits gastric acid secretion by an opioid dependent mechanism and that the dose of naloxone was sufficient to abolish the gastric inhibitory effect of a high dose $\left(1 \mathrm{nmol} \cdot \mathrm{kg}^{-1}\right)$ of $\beta$-endorphin. Furthermore, $\beta$-endorphin $\left(2 \mathrm{nmol} \cdot \mathrm{kg}^{-1}\right)$ injected intravenously did not inhibit pentagastrin-stimulated $\left(4 \mu \mathrm{g} \cdot \mathrm{kg} \cdot \mathrm{h}^{-1}\right)$ gastric acid secretion, suggesting that $\beta$-endorphin acts within the brain to inhibit gastric acid secretion when injected i.c.v.

To determine if the inhibitory effect of CRF given i.c.v. was reproducible, CRF ( $2 \mathrm{nmol} \cdot \mathrm{kg}^{-1}$ ) or control (sterile water) was given i.c.v. on two separate days and $4 \mathrm{wk}$ later on two other days $15 \mathrm{~min}$ before a 3-h pentagastrin infusion $\left(4 \mu \mathrm{g} \cdot \mathrm{kg}^{-1} \cdot \mathrm{h}^{-1}\right)$. On the first occasion, the mean $( \pm \mathrm{SE})$ total acid outputs after control and CRF were $47.2 \pm 2.7$ and $23.5 \pm 1.3 \mathrm{mmol} \cdot 3 \mathrm{~h}^{-1}(P<0.01)$, respectively, and on the second occasion they were $44.6 \pm 4.0$ and $20.6 \pm 2.1 \mathrm{mmol} \cdot 3 \mathrm{~h}^{-1}$ $(P<0.01)$, respectively. These results indicate that the gastric inhibitory effect of CRF given i.c.v. was highly reproducible. Furthermore, because the secretory responses between the first and second tests were similar and not significantly different compared with the averages of both, it was decided to perform further studies in each of the four animals only once.

Statistical analysis. Results are depicted as means $( \pm \mathrm{SE})$ obtained from experiments performed in four animals. The data were subjected

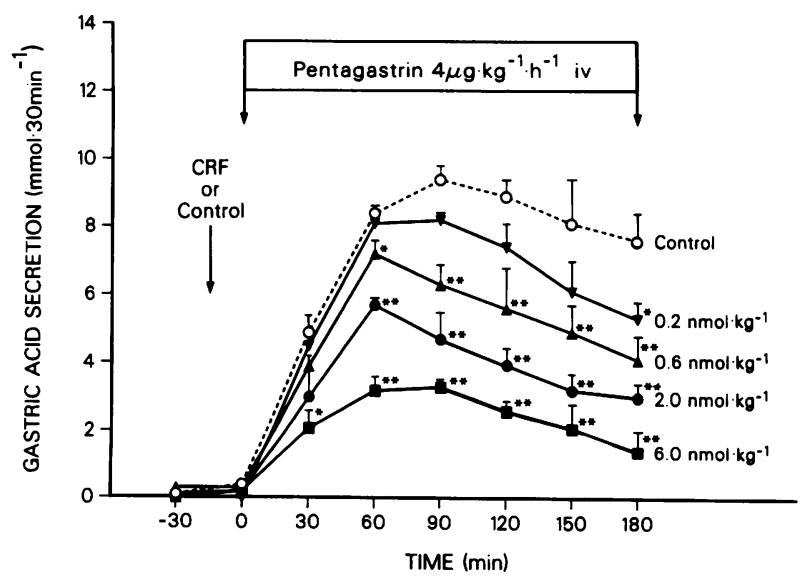

Figure 1. Effect of i.c.v. administration of ovine CRF on pentagastrin-stimulated gastric acid secretion in conscious dogs. In this and in all subsequent figures, results obtained from four dogs are depicted as means \pm SE. ${ }^{*} P<0.05 ;{ }^{* *} P<0.01$ compared with the corresponding time points of control.

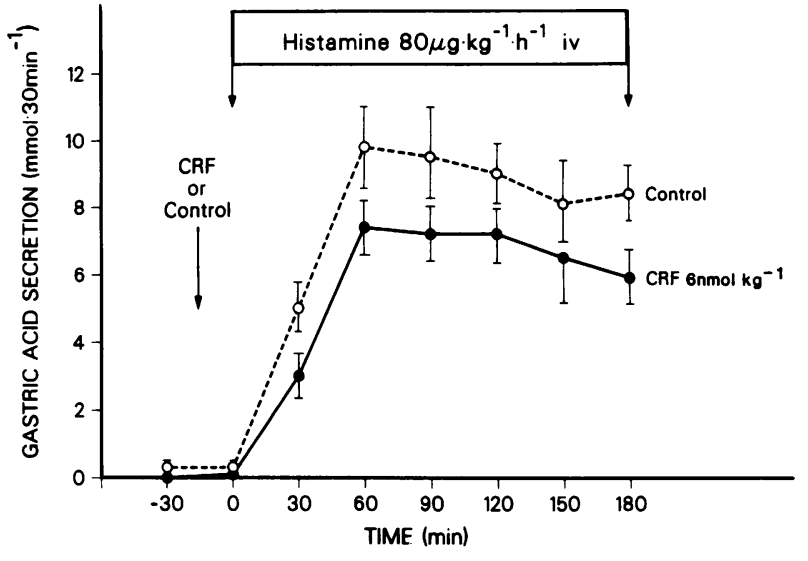

Figure 2. Effect of i.c.v. administration of CRF on histamine-stimulated gastric acid secretion. Differences between CRF and control were not significant.

to analysis of variance, and differences between treatment groups were assessed with the multiple range tests of Dunnett and Duncan (23).

\section{Results}

Effects of CRF on gastric acid secretion. CRF microinjected into the third cerebral ventricle inhibited pentagastrin-stimulated gastric acid secretion for $3 \mathrm{~h}$ in a dose-dependent fashion (Fig. 1). Based on the calculated 3-h total acid outputs, the half-maximal effective dose of CRF that inhibited pentagastrinstimulated acid secretion was $2 \mathrm{nmol} \cdot \mathrm{kg}^{-1}$. This dose of CRF was used in further studies to examine the mechanisms of its action in inhibiting acid secretion.

The highest dose of CRF $\left(6 \mathrm{nmol} \cdot \mathrm{kg}^{-1}\right)$ that inhibited the pentagastrin-stimulated 3-h total acid output by $68 \%$ did not significantly decrease histamine-stimulated gastric acid secretion (Fig. 2). In contrast, the half-maximal effective dose (2 $\mathrm{nmol} \cdot \mathrm{kg}^{-1}$ ) decreased gastric acid secretion in response to 2-deoxy-D-glucose for $3 \mathrm{~h}$ (Fig. 3).

Effects of ganglionic blockade and vagotomy. Ganglionic blockade with chlorisondamine significantly $(P<0.05)$ decreased the pentagastrin-stimulated acid output by $45 \%$ in

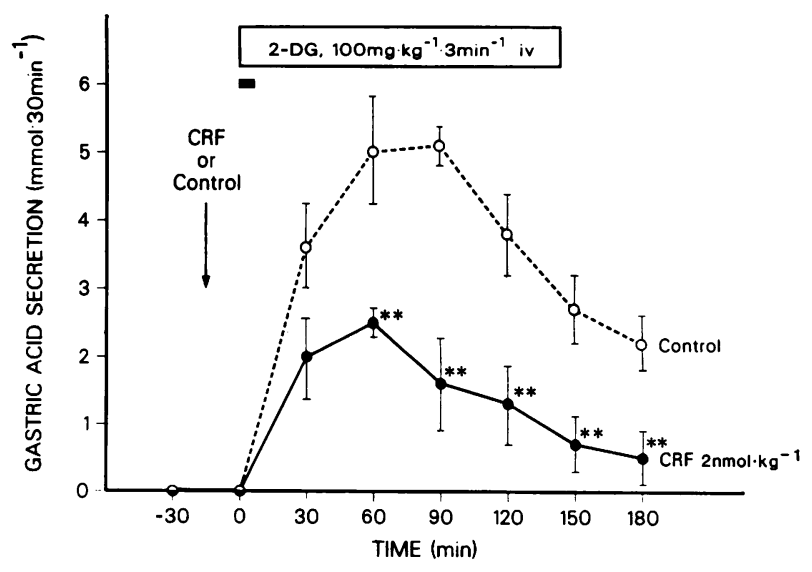

Figure 3. Effect of i.c.v. administration of CRF on gastric acid secretion stimulated by 2 -deoxy-D-glucose (2-DG). ${ }^{* *} P<0.01 \mathrm{com}$ pared with control. 


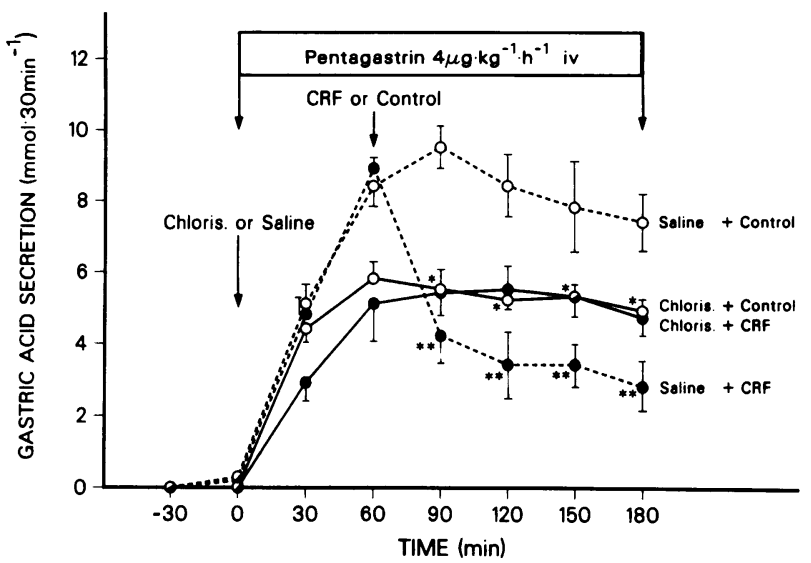

Figure 4. Effect of ganglionic blockade with chlorisondamine (Chloris., $0.5 \mathrm{mg} \cdot \mathrm{kg}^{-1}$, i.v.) on CRF $\left(2 \mathrm{nmol} \cdot \mathrm{kg}^{-1}\right.$, i.c.v.)-induced inhibition of gastric acid secretion. ${ }^{*} P<0.05$; ${ }^{* *} P<0.01$ compared with saline plus control. Chlorisondamine completely prevented the gastric inhibitory action of CRF administered i.c.v.

control experiments (Fig. 4). Although CRF given i.c.v. significantly $(P<0.1)$ decreased gastric acid secretion by $65 \%$ in the saline-treated group, the same dose of CRF $\left(2 \mathrm{nmol} \cdot \mathrm{kg}^{-1}\right)$ did not inhibit gastric acid secretion in chlorisondaminetreated animals (Fig. 4). After i.c.v. injection of CRF, acid outputs were greater, yet insignificantly, in the animals treated with chlorisondamine compared with the acid outputs in the saline-treated group.

Before truncal vagotomy, CRF given i.c.v. decreased the pentagastrin-stimulated acid output by $\sim 65 \%$ and to a similar degree as vagotomy alone (Fig. 5). However, in contrast to ganglionic blockade, vagotomy did not prevent the gastric inhibitory action of CRF administered i.c.v. Immediately after injection, CRF significantly $(P<0.01)$ decreased pentagastrinstimulated acid secretion in vagotomized dogs (Fig. 5).

Effects of vasopressin and opioid antagonists. Injection intravenously of the vasopressin antagonist [1-deaminopenicillamine,2-( $O$-methyl)tyrosine,8-arginine]-vasopressin $60 \mathrm{~min}$ before i.c.v. injection of CRF significantly reversed the gastric inhibitory action of CRF on pentagastrin-stimulated gastric acid secretion (Fig. 6). The vasopressin antagonist by itself did

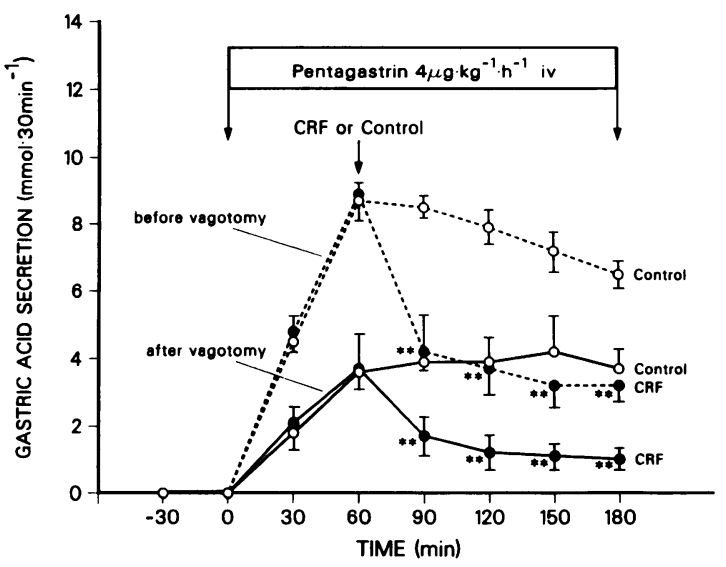

Figure 5. Effect of truncal vagotomy on CRF $\left(2 \mathrm{nmol} \cdot \mathrm{kg}^{-1}\right.$, i.c.v.)induced inhibition of gastric acid secretion. ${ }^{* *} P<0.01$ compared with the appropriate control.

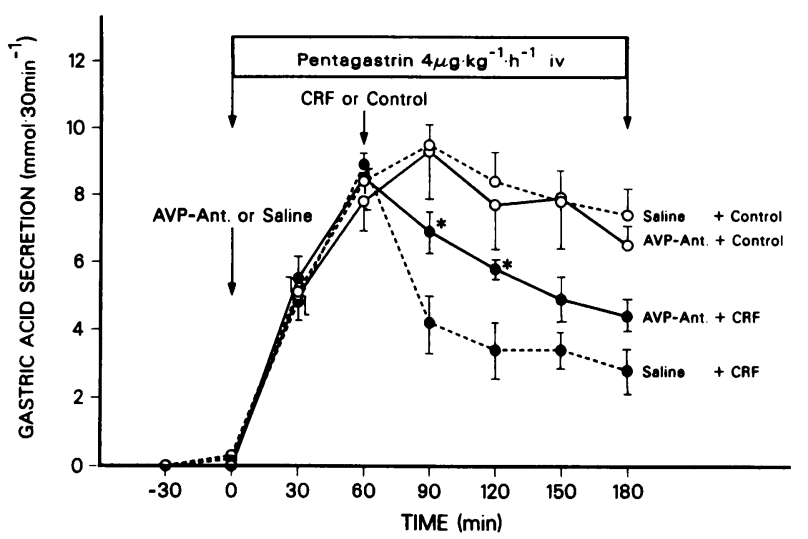

Figure 6. Effect of a vasopressin antagonist (AVP-Ant., 200 $\mathrm{nmol} \cdot \mathrm{kg}^{-1}$, i.v.) on CRF $\left(2 \mathrm{nmol} \cdot \mathrm{kg}^{-1}\right.$, i.c.v.)-induced inhibition of gastric acid secretion. ${ }^{*} P<0.05$ compared with saline plus $C R F$.

not alter the secretory response compared with the salinetreated control (Fig. 6).

Pretreatment of the animals with the opioid antagonist naloxone $60 \mathrm{~min}$ before i.c.v. injection of CRF significantly prevenied the gastric inhibitory action of CRF on pentagastrinstimulated acid secretion for $2 \mathrm{~h}$ (Fig. 7). Naloxone by itself did not affect the gastric secretory response after pentagastrin (Fig. 7).

Effects of CRF on meal-stimulated gastric acid secretion and plasma gastrin. Administration i.c.v. of CRF 15 min before intragastric infusion of a 200 -ml liquid peptone meal resulted in dose-dependent inhibition of gastric acid secretion in conscious dogs (Fig. 8). A dose of $2 \mathrm{nmol} \cdot \mathrm{kg}^{-1}$ that was tested in the peptone studies and that inhibited the 2-h mealstimulated total acid output by $74 \%$ did not alter plasma gastrin concentrations compared with control experiments (Fig. 9).

\section{Discussion}

CRF exhibits an array of biologic actions other than the expected stimulation of ACTH and $\beta$-endorphin release from the pituitary (1, 5-14). CRF administered i.c.v. activates the sympathetic nervous system in rats (5) and in dogs (12). The

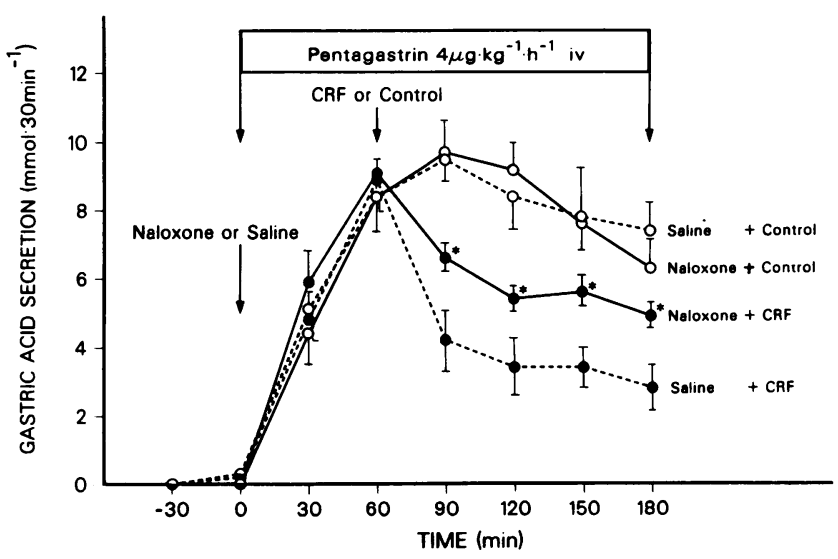

Figure 7. Effect of an opioid antagonist, naloxone $\left(1 \mathrm{mg} \cdot \mathrm{kg}^{-1}\right.$, i.v.), on CRF ( $2 \mathrm{nmol} \cdot \mathrm{kg}^{-1}$, i.c.v.)-induced inhibition of gastric acid secretion. ${ }^{*} P<0.05$ compared with saline plus CRF. 


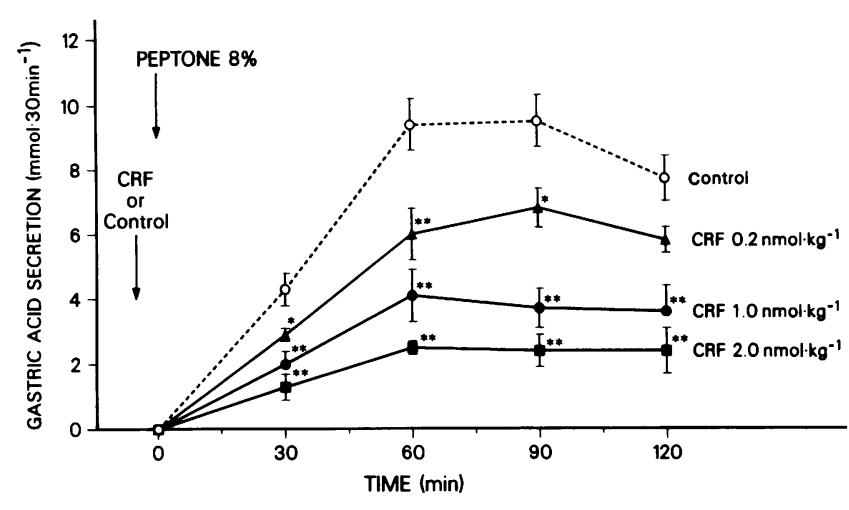

Figure 8. Effect of i.c.v. administration of CRF on meal-stimulated gastric acid secretion during intragastric titration at $\mathrm{pH} 5.0 .{ }^{*} P$ $<0.05 ;{ }^{* *} P<0.01$ compared with control.

purpose of this study was to examine the central nervous system effects of CRF on gastric acid secretion and to assess the role of the autonomic nervous system (14) in mediating the biologic actions of CRF in conscious dogs.

CRF administered i.c.v. inhibited gastric acid secretion stimulated by pentagastrin and 2-deoxy-D-glucose but not by histamine. Histamine is a more potent vasodilator (24) and more resistant to acid inhibition by catecholamines (25) than pentagastrin. These findings may explain that CRF injected i.c.v., although it increased plasma catecholamine concentrations $(5,12)$, did not significantly decrease histamine-stimulated gastric acid secretion. Although this study was designed to examine the central nervous system effects of CRF on gastric acid secretion, no conclusions can be made regarding the peripheral mechanisms that underlie CRF-induced inhibition of gastric secretion.

Stimulatory and inhibitory efferents of the central nervous system regulate autonomic responses, including the secretion of gastric acid. Whereas activation of the sympathetic nervous system results in a decrease of gastric acid secretion, presumably by shutting down gastric blood flow (24), stimulation of the parasympathetic nervous system predominantly results in an increase of gastric acid secretion by the release of acetylcholine from vagal postganglionic nerve endings (26) and gastrin from antral G-cells (27). CRF administered i.c.v. activates the sympathetic nervous system in rats (5) and in dogs (12), increasing

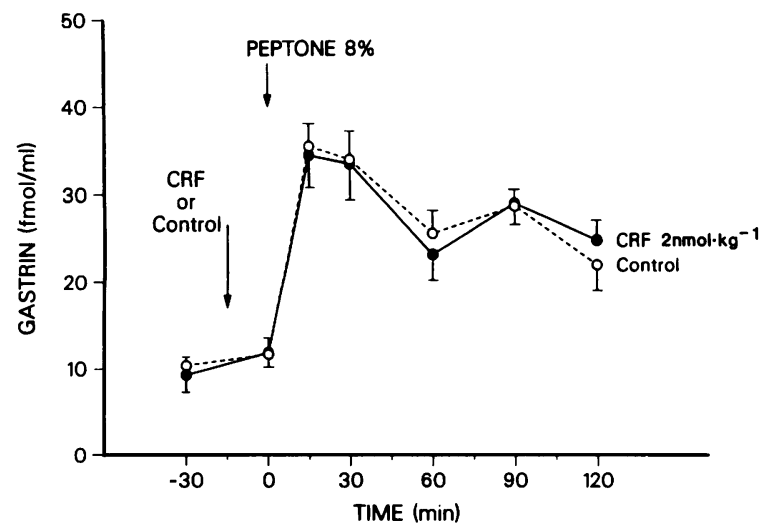

Figure 9. Effect of i.c.v. administration of CRF on meal-stimulated plasma gastrin concentrations during intragastric titration at pH 5.0. No significant differences between CRF and control were observed. mean arterial pressure and plasma catecholamine concentrations. To determine whether CRF administered i.c.v. decreases gastric acid secretion by also increasing sympathetic or by withdrawing parasympathetic outflow, ganglionic blockade and truncal vagotomy were performed. Chlorisondamine, a biquaternary ammonium compound that does not penetrate the blood-brain barrier and produces blockade of sympathetic and parasympathetic ganglia by occupying acetylcholine receptor sites (28), completely abolished the gastric inhibitory effect of CRF. Therefore, gastric acid inhibition induced by i.c.v. injection of CRF appears to be mediated at least in part by the autonomic nervous system. In contrast, bilateral truncal vagotomy did not alter the gastric inhibitory action of CRF given i.c.v. Assuming that vagotomy resulted in complete interruption of parasympathetic efferents to the stomach, as assessed by the negative 2-deoxy-D-glucose test (22), our data indicate that CRF administered i.c.v. does not inhibit gastric acid secretion by vagal, parasympathetic withdrawal. Therefore, in conscious dogs, gastric acid inhibition induced by i.c.v. administration of CRF appears to be the result of activation of the sympathetic nervous system and not the result of parasympathetic withdrawal. In the rat, CRF-induced inhibition of gastric acid secretion was completely prevented by acute adrenalectomy and, in part, by truncal vagotomy (11). The differences between the effect of vagotomy on CRF-induced gastric acid inhibition in the latter study (11) and in this report are not understood, but may be due to species differences or the effect of anesthesia used in the former report (11).

CRF stimulates the release of ACTH and $\beta$-endorphin from pituitary cells in vitro and in vivo (1). $\beta$-Endorphin inhibited gastric acid secretion in rats after i.c.v., but not after intravenous administration (29). Also, we demonstrated that $\beta$-endorphin injected i.c.v., but not intravenously decreased pentagastrin-stimulated gastric acid secretion in conscious dogs. In agreement with these studies, $\beta$-endorphin given intravenously to humans does not affect gastric acid secretion (30). Furthermore, the gastric inhibitory effect of $\beta$-endorphin given i.c.v. was completely abolished by pretreatment with the opioid antagonist naloxone. These findings indicate that $\beta$-endorphin acts within the brain to inhibit gastric acid secretion by an opiate-dependent pathway. Inhibition of gastric acid secretion induced by i.c.v. administration of CRF also was partly reversed by naloxone, suggesting that $C R F$ decreases gastric acid secretion in part by an opiate-sensitive mechanism. CRF releases $\beta$-endorphin from the pituitary into the peripheral circulation (1). Because $\beta$-endorphin administered intravenously does not alter gastric acid secretion, it seems unlikely that i.c.v. administered CRF decreases gastric acid secretion by increasing the level of peripherally circulating $\beta$-endorphin. However, $\beta$-endorphin-like immunoreactivity is found within the central nervous system (31), and CRF pathways project to $\beta$-endorphin-containing neuronal cells (4). Therefore, it is possible that CRF decreases gastric acid secretion by increasing the release of either $\beta$-endorphin or another naloxone-sensitive opioid within the brain.

CRF administered i.c.v. increases plasma vasopressin concentrations in conscious dogs (12). Vasopressin administered intravenously decreases gastric acid secretion presumably by decreasing gastric mucosal blood flow (24). Inhibition of gastric acid secretion induced by i.c.v. injection of CRF was in part prevented by the vasopressin antagonist [1-deaminopenicillamine,2-( $O$-methyl)tyrosine,8-arginine]-vasopressin. Therefore, 
CRF-induced inhibition of gastric acid secretion appears to be in part mediated by a vasopressin-sensitive mechanism. In contrast to $\beta$-endorphin that inhibits gastric acid secretion after central but not after peripheral administration, vasopressin inhibits gastric acid secretion after peripheral but not after central administration. Also, vasopressin-induced inhibition of gastric acid secretion is not affected by ganglionic blockade with chlorisondamine (unpublished observations). These findings suggest that vasopressin released by CRF decreases gastric acid secretion by a peripheral mechanism of action, possibly by decreasing gastric mucosal blood flow (24).

The gastric inhibitory action of CRF in the rat was not prevented by hypophysectomy (11), indicating that pituitarysecreted vasopressin was not a critical link in the antisecretory effect of CRF. Of interest, a vasopressin-like peptide is widely distributed in noradrenergic neurones of ganglia of the sympathetic nervous system in mammals (32). In that CRF acts within the central nervous system to increase sympathetic outflow $(5,12)$, it is possible that CRF-induced activation of the sympathetic nervous system in the dog results in vasopressin release from noradrenergic neurons increasing the concentration of vasopressin locally in the gastric circulation and systemically in peripheral vascular beds (32). This explanation is consistent with our finding that ganglionic blockade of the autonomic nervous system completely prevented the gastric inhibitory effect of CRF, including the vasopressin-dependent pathway.

CRF microinjected into the third cerebral ventricle also inhibited gastric acid secretion stimulated by a protein (peptone) meal in a dose-dependent fashion. Because CRF did not alter plasma gastrin concentrations while the $\mathrm{pH}$ of the intragastric meal was held constant at pH 5.0, CRF-induced inhibition of meal-stimulated gastric acid secretion is not mediated by a decrease of gastrin release.

Although the role of CRF as a physiologic regulator of gastric acid secretion remains to be further established, immunohistochemical studies suggest that CRF may be involved in the central mediation of gastrointestinal responses (4). CRFimmunoreactive cells and fibers are distributed in those regions of the central nervous system that participate in the regulation of gastric secretion and motility, i.e., lateral hypothalamic area (33), central nucleus of the amygdala (34), and dorsal vagal complex (35). Whereas this study and a previous report (12) indicate that CRF administered i.c.v. acts within the central nervous system in the dog to exert biologic actions, the present study does not provide evidence for specific sites of action of CRF within the dog brain. In the rat, CRF injected into the lateral hypothalamus inhibited gastric acid secretion (11). Further studies are needed to precisely examine the specific site(s) of action of CRF within the central nervous system to inhibit gastric acid secretion in the dog.

CRF acts within the central nervous system eliciting endocrine and autonomic responses that are characteristic of stress reactions: ACTH and $\beta$-endorphin release $(1,13)$, activation of the sympathetic nervous system (5-8), hyperglycemia (5), and increased mean arterial pressure and heart rate (6). Stressful events may induce a decrease in gastric acid secretion and microcirculation and may give rise to gastric erosions and ulcerations (36). Because CRF appears to be a physiologic regulator of ACTH secretion and the autonomic nervous system under basal and stressful circumstances $(13,14)$, it is tempting to speculate that CRF may also mediate the decrease of gastric acid secretion in response to some forms of stress.
In summary, the results of this study indicate that CRF acts within the central nervous system to decrease gastric acid secretion in conscious dogs. CRF-induced inhibition of gastric acid secretion appears to be mediated by activation of the sympathetic nervous system and, in part, by opiate and vasopressin-dependent pathways. The gastric inhibitory action of CRF microinjected into the third cerebral ventricle is not mediated by the vagus nerves or a decrease of gastrin release. The physiologic importance of CRF as a central regulator in mediating the gastric secretory responses to stress remains to be determined.

\section{Acknowledgments}

The authors thank Dr. J. E. Rivier for providing the peptides, Dr. W. W. Vale for CRF measurements, Dr. R. P. Saik for performing the vagotomy and pyloroplasty, Dr. F. J. Ho and Mr. P. Chew in the laboratory of Dr. J. H. Walsh for gastrin measurements, Dr. Ch. F. Code and Dr. J. I. Isenberg for thoughtful comments, Ms. V. J. Webb for expert technical assistance, and Ms. Susan Logan for manuscript preparation.

This research was supported by grant AM-26741 from the National Institutes of Health and grant Le 470/1-2 from the Deutsche Forschungsgemeinschaft. It was conducted in part by the Clayton Foundation for Research, California Division. Dr. Brown is a Clayton Foundation Investigator.

\section{References}

1. Vale, W., J. Spiess, C. Rivier, and J. Rivier. 1981. Characterization of a 41-residue ovine hypothalamic peptide that stimulates secretion of corticotropin and $\beta$-endorphin. Science (Wash. DC). 213:13941397.

2. Rivier, J., J. Spiess, and W. Vale. 1983. Characterization of rat hypothalamic corticotropin-releasing factor. Proc. Natl. Acad. Sci. USA. 80:4851-4855.

3. Furutani, Y., Y. Morimoto, S. Shibahara, M. Noda, H. Takahashi, T. Hirose, M. Asai, S. Inayama, H. Hayashida, T. Miyata, and S. Numa. 1983. Cloning and sequence analysis of cDNA for ovine corticotropin-releasing factor precursor. Nature (Lond.). 301:537-540.

4. Swanson, L. W., P. E. Sawchenko, J. Rivier, and W. W. Vale. 1983. Organization of ovine corticotropin-releasing factor immunoreactive cells and fibres in the rat brain: an immunohistochemical study. Neuroendocrinology. 36:165-186.

5. Brown, M. R., L. A. Fisher, J. Spiess, C. Rivier, J. Rivier, and W. Vale. 1982. Corticotropin-releasing factor: actions on the sympathetic nervous system and metabolism. Endocrinology. 111:928-931.

6. Fisher, L. A., J. Rivier, C. Rivier, J. Spiess, W. Vale, and M. R. Brown. 1982. Corticotropin-releasing factor (CRF): central effects on mean arterial pressure and heart rate in rats. Endocrinology. 110: 2222-2224.

7. Brown, M. R., L. A. Fisher, J. Rivier, J. Spiess, C. Rivier, and W. Vale. 1982. Corticotropin-releasing factor: effects on the sympathetic nervous system and oxygen consumption. Life Sci. 30:207-210.

8. Sutton, R. E., G. F. Koob, M. LeMoal, J. Rivier, and W. Vale. 1982. Corticotropin-releasing factor produces behavioral activation in rats. Nature (Lond.). 297:331-333.

9. Sirinathsinghji, D. J. S., L. H. Rees, J. Rivier, and W. Vale. 1983. Corticotropin-releasing factor is a potent inhibitor of sexual receptivity in the female rat. Nature (Lond.). 305:232-235.

10. Morley, J. E., and A. S. Levine. 1982. Corticotropin-releasing factor, grooming and ingestive behavior. Life Sci. 31:1459-1464.

11. Tache, Y., Y. Goto, M. W. Gunion, W. Vale, J. Rivier, and M. Brown. 1983. Inhibition of gastric acid secretion in rats by intracerebral injection of corticotropin-releasing factor. Science (Wash. DC). 222:935-937. 
12. Brown, M. R., and L. A. Fisher. 1983. Central nervous system effects of corticotropin-releasing factor in the dog. Brain Res. 280:7579.

13. Rivier, J., C. Rivier, and W. Vale. 1984. Synthetic competitive antagonists of corticotropin-releasing factor: effect on ACTH secretion in the rat. Science (Wash. DC). 224:889-891.

14. Brown, M. R., and L. A. Fisher. 1985. Corticotropin-releasing factor: effects on the autonomic nervous system and visceral systems. Fed. Proc. 44:243-248.

15. Dua-Sharma, S., K. N. Sharma, and H. L. Jacobs. 1970. The Canine Brain in Stereotaxic Coordinates: Full Sections in Frontal, Sagittal and Horizontal Planes. MIT Press, Cambridge, MA. 211 pp.

16. Thomas, J. E. 1941. An improved cannula for gastric and intestinal fistulas. Proc. Soc. Exp. Biol. Med. 46:260-261.

17. Jordan, P. H., Jr. 1983. Peptic ulcer disease and early postoperative complications. In Gastrointestinal Disease: Pathophysiology, Diagnosis, Management. M. S. Sleisenger and J. H. Fordtran, editors. W. B. Saunders, Philadelphia. 739-749.

18. Isenberg, J. I. 1978. Gastric secretory testing. In Gastrointestinal Disease: Pathophysiology, Diagnosis, Management. M. H. Sleisenger and J. S. Fordtran, editors. W. B. Saunders, Philadelphia. 714-732.

19. Fordtran, J. S., and J. H. Walsh. 1973. Gastric acid secretion rate and buffer content of the stomach after eating. Results in normal subjects and in patients with duodenal ulcer. J. Clin. Invest. 52:645657.

20. Rosenquist, G. L., and J. H. Walsh. 1980. Radioimmunoassay of gastrin. In Gastrointestinal Hormones. G. B. Jerzy Glass, editor. Raven Press, New York. 769-795.

21. Vale, W., J. Vaughan, G. Yamamoto, T. Bruhn, C. Douglas, D. Dalton, C. Rivier, and J. Rivier. 1983. Assay of corticotropinreleasing factor. Methods Enzymol. 103:565-577.

22. Eisenberg, M. M., G. S. Emas, and M. I. Grossman. 1966. Comparison of the effect of 2-deoxy-D-glucose and insulin on gastric acid secretion in dogs. Surgery (St. Louis). 60:111-117.

23. Zar, J. H. 1974. Biostatistical analysis. Prentice-Hall, Englewood Cliffs. 620 pp.

24. Guth, P. H., and K. W. Ballard. 1981. Physiology of the gastric circulation. In Physiology of the Gastrointestinal Tract. L. R. Johnson, editor. Raven Press, New York. 709-731.

25. McCloy, R. F., V. A. Dawson, and J. H. Baron. 1979. The effect of salbutamol and propranolol on pentagastrin, histamine and meal-stimulated acid and pepsin secretion in the dog. Acta HepatoGastroenterol. 26:399-406.

26. Hirschowitz, B. I., and G. Sachs. 1965. Vagal gastric secretory stimulation by 2-deoxy-D-glucose. Am. J. Physiol. 209:452-460.

27. Tepperman, B. L., J. H. Walsh, and R. M. Preshaw. 1972. Effect of antral denervation on gastrin release by sham feeding and insulin hypoglycemia in dogs. Gastroenterology. 63:973-980.

28. Taylor, P. 1980. Ganglionic stimulating and blocking agents. In The Pharmacological Basis of Therapeutics. A. Goodman Gilman, L. S. Goodman, and A. Gilman, editors. Macmillan Publishing Co., Inc., New York. 211-219.

29. Roze, C., M. Dubrasquet, J. Chariot, and C. Vaille. 1980. Central inhibition of basal pancreatic and gastric secretion by $\beta$ endorphin in rats. Gastroenterology. 79:659-664.

30. Feldman, M., and C. H. Li. 1982. Effect of $\beta$-endorphin on gastric acid secretion and serum gastrin concentration in humans. Regul. Pept. 4:311-315.

31. Watson, S. J., C. W. Richard, and J. D. Barchas. 1978. Adenocorticotropin in rat brain: immunocytochemical localization in cells and axons. Science (Wash. DC). 200:1180-1182.

32. Hanley, M. R., H. P: Benton, S. L. Lightman, K. Todd, E. A. Bone, P. Fretten, S. Palmer, C. J. Kirk, and R. H. Michell. 1984. A vasopressin-like peptide in the mammalian sympathetic nervous system. Nature (Lond.). 309:258-261.

33. Misher, A., and F. P. Brooks. 1966. Electrical stimulation of hypothalamus and gastric secretion in the albino rat. Am. J. Physiol. 211:403-406.

34. Shealy, C. N., and T. L. Peele. 1957. Studies on the amygdaloid nucleus of cat. $J$. Neurophysiol. 20:125-139.

35. Kerr, F. W. L., and R. M. Preshaw. 1969. Secretomotor function of the dorsal motor nucleus of the vagus. J. Physiol. (Lond.). 205:405-415.

36. Guth, P. H. 1982. Pathogenesis of gastric mucosal injury. Annu. Rev. Med. 33:183-196. 